\title{
PET and PET/CT Imaging for the Earliest Detection and Treatment of Colorectal Carcinoma
}

\author{
Kevin Carter $^{1}$ and Eduard Kotlyarov ${ }^{2 *}$ \\ ${ }^{1}$ Michigan State University; POH Medical Center; Pontiac, Michigan - USA. ${ }^{2}$ Michigan State University and \\ Georgetown University; POH Medical Center; Pontiac; Michigan - USA. POH Medical Center; 50 Perry Street; \\ Pontiac; 48342; Michigan - USA
}

\begin{abstract}
Approximately 150,000 new cases of colorectal cancer are diagnosed each year with the life time risk of developing colon caner in developed nations being $4.6 \%$ in men and $3.2 \%$ in women. Screening patients is essential early detection of colon carcinoma to aid in complete resection. Unfortunately current screening methods carry with them poor patient compliance. PET and PET/CT may be a significant part of this screening solution. The authors reviewed and analyzed the English language articles and case reports identified on Medline during the last 10 years. PET and PET/CT results for colorectal carcinoma were tabulated and presented for the fifth Scientific Meeting of the Brazilian Society of Nuclear Biosciences. Though most studies have been retrospective analysis in using PET for staging for other malignant processes the cases that have identified additional uptake in the colon are important. The accuracy when utilizing PET and PET/CT in this screening method has a sensitivity between 65 and $90 \%$ with a specificity of 84 to $90 \%$ and a positive predictive value 71 to $78 \%$. Early stages of malignancies and pre-cancerous polyps avidly accumulates F-18 Deoxyflouro glucose allowing us to conclude that whole body PET and PET/CT is an essential component in the work up, staging or treatment monitoring in colon carcinoma. We have to continue to accumulate data for possible introduction for whole body PET and PET/CT scanning for colon carcinoma and precancerous polyps.
\end{abstract}

Key words: PET and PET/CT, colorectal cancer, diagnostic

\section{INTRODUCTION}

Approximately 150,000 new cases of colorectal cancer are diagnosed each year. It is second only to lung cancer as the cause of cancer deaths in the United States. There is an established high incidence of colorectal carcinoma in developed nations around the world. Unfortunately the life time risk of developing colon cancer in developed nations is $4.6 \%$ in men and $3.2 \%$ in women 1 .

Colon carcinoma is generally found in patients greater than fifty years old. The incidence of this carcinoma has not changed in the last forty years, but recently mortality rates have improved. The current five year survival rate is approximately $61 \%$ from the time of diagnosis 1 .

Colon carcinomas develop within preexisting foci of adenomatous tissue. This almost always occurs in a polypoid lesion because adenomatous change has rarely been seen to develop in intact mucosa. The size of the polyp is extremely important. Polyps $1.5 \mathrm{~cm}$ in size or less carry a less than $2 \%$ risk of developing into colon cancer, but as the polyp grows in size, risk for developing carcinoma

*Author for correspondence 
increases. Polyps that are $2.5 \mathrm{~cm}$ or greater in size have a risk than is greater than $10 \%$ of developing into colon cancer. (Table I).

There are many risk factors that may contribute to developing to colorectal cancer, these include: age, diet, genetic factors, predisposing medical conditions, and a smoking history1. Any person greater than 40 years old is already at an increased risk for developing colon cancer, the peak age of onset in the United States is 65. Western diets also contribute to colon carcinoma risk, this includes being high in animal fats, which is felt to expose the colon to an elevated level of carcinogens. Also diets low in fiber, which result in increased colonic transit time lead to prolonged exposure to colonic carcinogens. Finally, it is felt that diets low in calcium and folate may contribute to an increased risk1. Their relationship is still being investigated. It has been well established that underlying medial conditions will predispose certain patients for developing colon cancer. These include having a history of inflammatory bowel disease, either ulcerative colitis or Crohn's disease. In ulcerative colitis the risk is related to the extent and duration of disease. In Crohn's disease, the risk is related to the amount of colonic involvement, increased with more extensive colonic disease. A prior history of colorectal cancer or cancerous polyps will increase the likelihood of developing carcinoma. The incidence of metachronous colorectal cancer is $0.5 \%$ to $3 \% 1$.

\section{METHODS AND RESULTS}

The authors reviewed and analyzed the English language articles and case reports identified on Medline during the last 10 years. PET and PET/CT results for colorectal carcinoma were tabulated and presented for the fifth Scientific Meeting of the Brazilian Society of Nuclear Biosciences.

Screening patients is essential in helping to detect colon carcinoma early to aid in complete resection. Unfortunately current screening methods carry with them poor patient compliance.

PET and PET/CT may be a significant part of this screening solution. It has already been established in the diagnosis and staging of colon carcinoma. In 134 patients studied, PET alone showed an accuracy of $94 \%$ versus $81 \%$ for CT. In the preoperative workup of patients for staging, PET has already displayed it usefulness. In a study of
16 patients with malignant colon lesions, FDGPET imaging detected 13 areas of increased activity in the region of the colon and rectum. Twelve of these 13 were confirmed malignant by histology and one was flasly positive. This helped to illustrate PET's usefulness in imaging the colon and rectum. Some of the initial data concerning the use of PET in screening for colorectal carcinoma has come from Japan where members of a medical health club underwent whole body PET imaging for screening. Of these members there were three true positives, and no false negatives. Seven false positive results were observed in these participants, who underwent colonoscopic examination after screening because of positive PET results. One was found to have ulcerative colitis of the descending colon and the other seven were found to have proctitis. This illustrates one of the few concerns with PET that a high FDG uptake can be observed in localized inflammatory lesions which can result in false positive findings. The conclusions from this study were that primary colorectal cancer can be depicted with PET in the early stage. This same group later performed a retrospective study of 110 patients who underwent both PET and total colonoscopy. Of these patients, 59 adenomatous polyps, $5-30 \mathrm{~mm}$ in size were detected in 30 subjects by total colonoscopy. PET findings were positive for 14 of these 59 adenomas (24\%). The positivity rate for PET images rose with the increase in size of the adenomas. It was over $90 \%$ accurate in adenomas that were larger than $13 \mathrm{~mm}$ in size. Overall in the study the false-positive rate was $5.5 \%$ (6 out of 110 patients).

In an endoscopic validation of FDG-PET imaging, 39 patients underwent both FDG-PET and endoscopy in a 2 year period. In comparison with colonscopy FDG-PET had a sensitivity of 74\% and a specificity of $84 \%$. The positive predictive value of FDG-PET was $78 \%$. Again, FDG-PET failed to detect small polyps $(3-10 \mathrm{~mm}$ in size) in four patients. All of the false positive PET findings were due to inflammatory lesions.

In the recent study, as part of a PET exam for a second malignancy, not related to colon cancer, a total of 1,000 PET scans were reviewed where 16 (1.6\%) of these has a total of 20 focal sites of FDG uptake within the abdomen. Within this group 10 patients were biopsied for a total of 14 lesions (out of the original 20). 2 of the 14 were adenocarinoma, 6/14 were tubulovillous adenoma, $1 / 14$ were tubular adenoma and $3 / 14$ were 
peritoneal metastasis. 2 of 14 had no apparent abnormality, but six months later, an adenocarcinoma was discovered at this site. The remaining 6/20 were lost to followup, but had negative CT. Therefore $65 \%$ of focal uptake was either pre-malignant or a malignant lesion (Fig. 1). Numerous case reports have been described finding an unknown area of increased FDG uptake in the colorectal region during a PET scan for another reason. One of these describes a patient who was undergoing PET for staging a large tumor in her ascending colon. At PET there were two areas of increased uptake recognized, one in the ascending colon and the other in the left suprapubic region. This was followed up with laparoscopy showing the lesion in the distal portion of the ascending colon and also detected in the sigmoid colon with invasion of the posterior wall of the bladder and uterus. In another case report where a 71 year old male presented with acute abdominal pain and a known small-cell carcinoma, CT was performed that determined there to be an intussusception, but no abnormality was detected. PET was performed to evaluate the lung lesion and detected a synchronous colonic adenocarcinoma. In a large retrospective study that reviewed the records of 500 consecutive patients referred for evaluation of pulmonary nodules via PET, 197 had no previous clinical or radiographic evidence of abnormalities of the GI tract. Among these patients, 59 had diffuse colonic uptake in various segments of the colon. Seventeen of the patients had focal colonic uptake, five of which were proved to be colon cancer.

Table 1

\begin{tabular}{cc} 
Size & Risk of Developing Colon Cancer \\
\hline $1.5 \mathrm{~cm}$ or less & Less than $2 \%$ \\
1.5 to $2.5 \mathrm{~cm}$ & $2-10 \%$ \\
$2.5 \mathrm{~cm}$ or greater & Greater than $10 \%$ \\
\hline
\end{tabular}

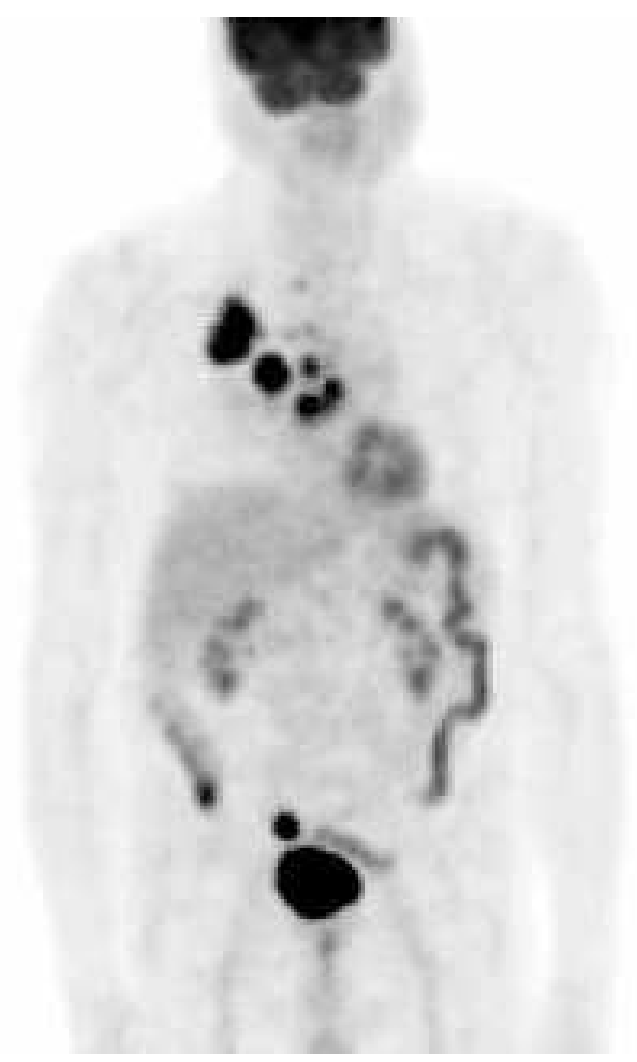

Figure 1 - 82 year old male presented for staging of lung carcinoma, was found to have two abnormal areas of FDG uptake in his colon. Following colonoscopy the focus in the sigmoid colon was a $3 \mathrm{~cm}$ tubulovillous adenoma, the focus in the cecum was also found to be a tubulovillous adenoma. 

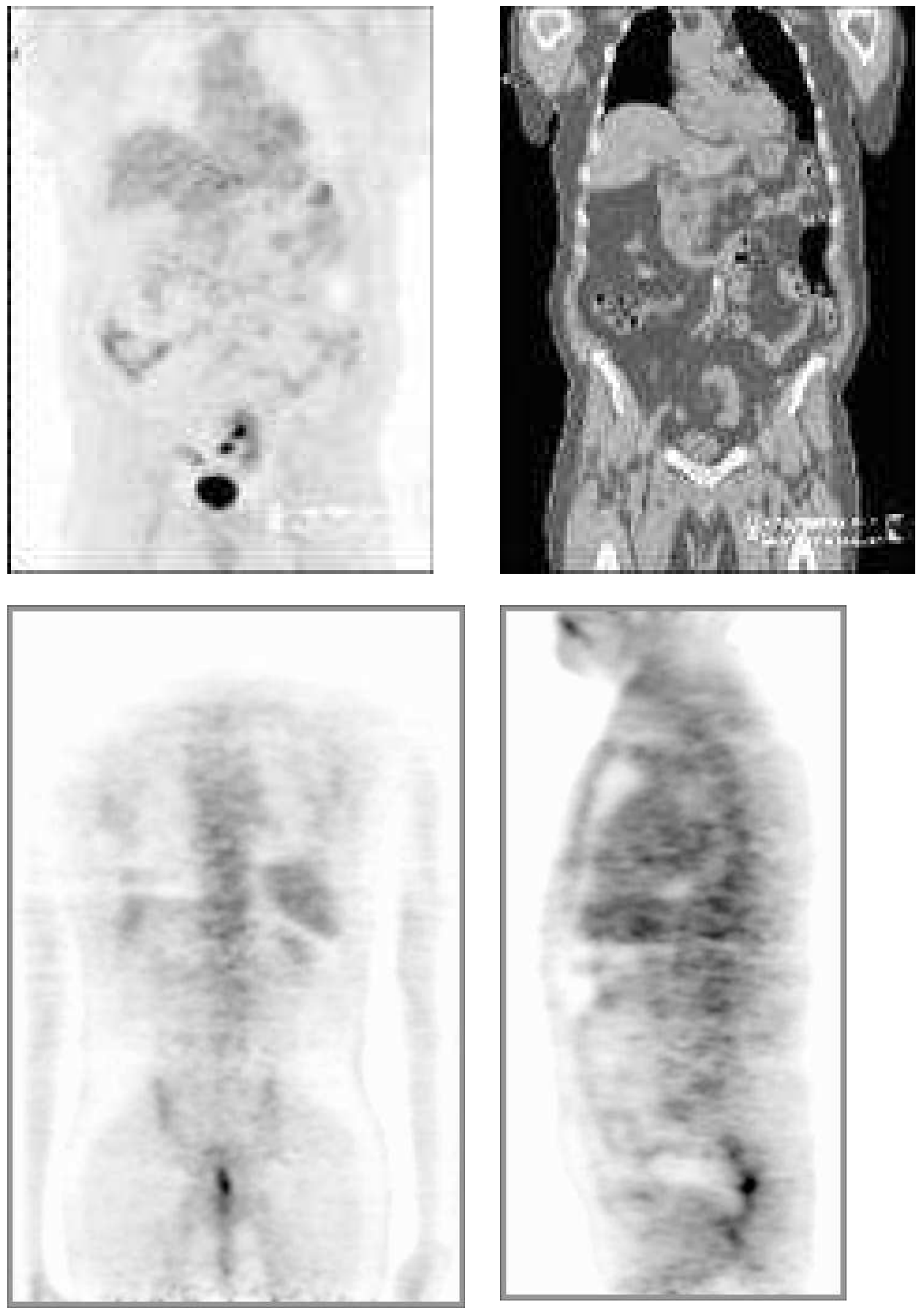

Figure 2 - The focal areas of uptake within the region of the sigmoid colon may be mistaken for a foci of carcinoma without correlation with the anatomic information provided by the CT. When correlated with the CT findings, it is clear that these foci of uptake are due to FDG being excreted by a normal pelvic kidney. 

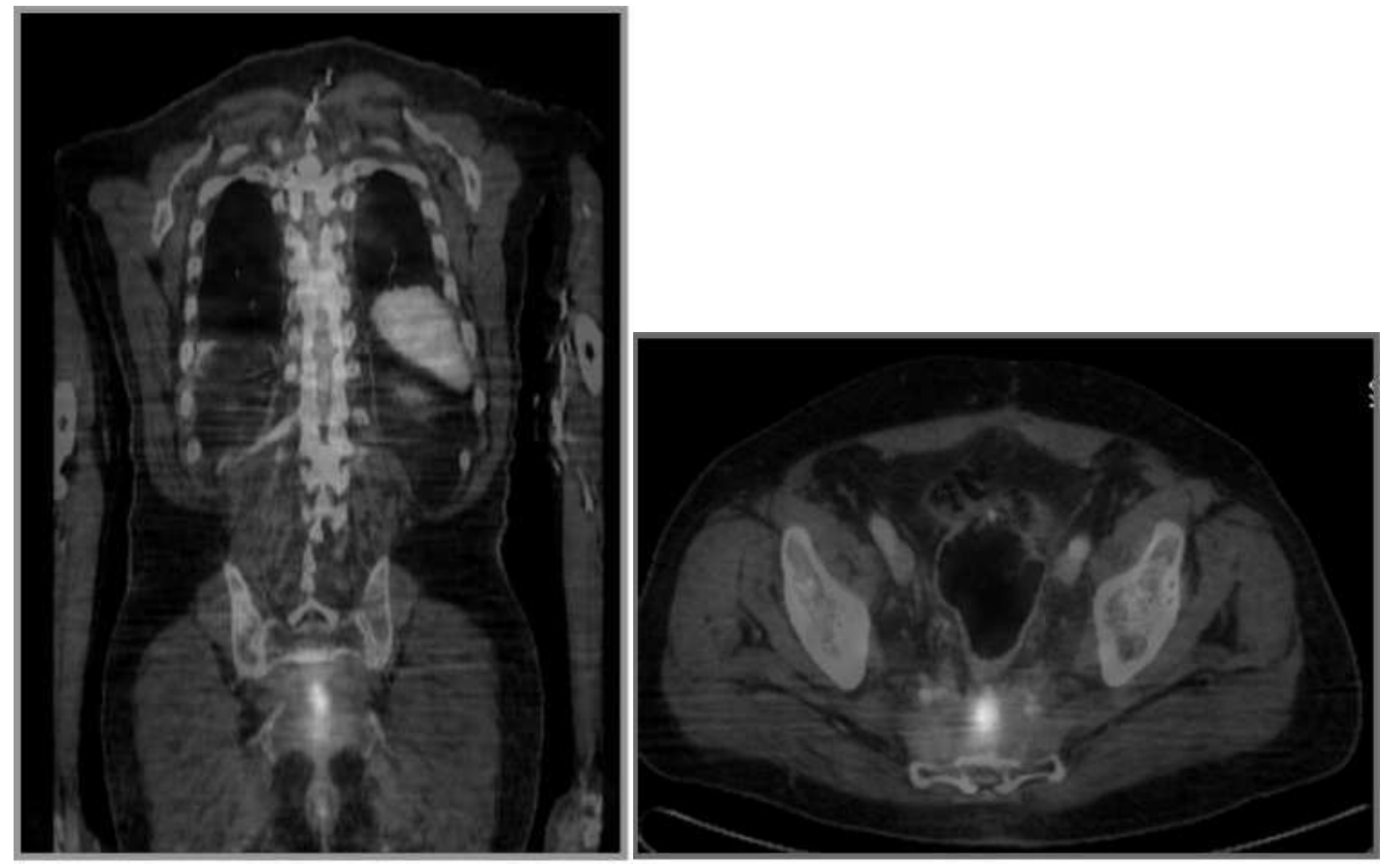

Figure 3 - This 70 year old male presented with a history of colon cancer and a rising CEA. Initial whole body PET images were non specific in the location for this localized uptake. Following fusion images with PET/CT the diagnosis of uptake in the presacral soft tissues which was consistant with recurrence. With the fusion images, this diagnosis was made with improved confidence.

Most recently a study of 1750 FDG-PET scans were obtained to evaluate a variety of known or suspected malignancies. In these cases, 58 abnormal, unexpected foci of hypermetabolism were identified in 53 patients. Among the 42 unexpected findings that had histopathologic confirmation, 30 foci in 25 patients were either malignant or premalignant tumors (positive predicitive value, $71 \%$ (30 of 42)). These included 18 colonic adenomas (six villous, four tubulovillous, and eight tubular) and three colonic adenocarcinomas.

Utilizing only PET for screening and identifying focal uptake in the abdomen poses a special problem due to the irregular uptake that can be observed in the intestine and other organs specifically the uterus, ureters, and pelvic musculature (Fig. 2). In this setting, PET/CT offers an important advantage because the CT component provides an anatomic framework for the PET findings, particularly in localizing FDG uptake to prevent false positive findings. The net effect of these PET/CT fusion images is improved confidence in distinguishing abnormal from physiologic uptake (See Figure 3). In a group of
3,270 Chinese patients who underwent screening PET/CT, 20 asymptomatic neoplasms were found in the colon (6 carcinomas and 14 adenomas). These lesions appeared as "hot spots" that were focal within the bowel. The PET/CT allowed for an improved confidence in this interpretation aiding in identifing if uptake was infact physiologic or pathologic. 12

The fact that early staging of malignancies and pre-cancerous polyps avidly accumulates F-18 Deoxyflouroglucose allows us to conclude that whole body PET Scanning, especially when combined with CT in fusion PET/CT images, is a must in everyday practice in the work up, staging or treatment monitoring in colon carcinoma. We have to continue to accumulate data for possible introduction for whole body PET/CT scanning for use in screening for colon carcinoma and precancerous polyps.

\section{CONCLUSIONS}

Early stages of malignancies and pre-cancerous polyps avidly accumulates F-18 Deoxyflouro 
glucose allowing us to conclude that whole body PET and PET/CT is an essential component in the work up, staging or treatment monitoring in colon carcinoma. We have to continue to accumulate data for possible introduction for whole body PET and PET/CT scanning for colon carcinoma and precancerous polyps.

\section{RESUMO}

Aproximadamente, 150000 novos casos de câncer coloretal são diagnosticados, anualmente, em países em desenvolvimento. Destes, 4,6\% em homens e 3,2\% em mulheres. A triagem de pacientes é essencial na detecção precoce do carcinoma de colon para ajudar na completa ressecção. Infelizmente, os métodos de exame atualmente disponíveis contam com uma baixa adesão dos pacientes. Parte significativa da solução desse problema pode estar no uso de PET e PET/CT. Os autores revisaram e analisaram os artigos e relatos de casos disponíveis no idioma inglês encontrados no Medline durante os últimos 10 anos. Para o Quinto Encontro Científico da Sociedade Brasileira de Biociências Nucleares, foram tabulados e apresentados os resultados de PET e PET/CT para carcinoma coloretal. Embora muitos casos têm sido resultados de uma análise retrospectiva do uso de PET para o estadiamento de outros processos malignos, aqueles casos que apresentaram uma captação adicional no colon foram considerados importantes. A precisão de PET e PET/CT como método de triagem tem sensibilidade entre $65 \%$ e $90 \%$ com especificidade de $84 \%$ a $90 \%$ e um valor preditivo positivo entre $71 \%$ a $78 \%$. Estágios iniciais de malignidade e pólipos pré-cancerosos apresentaram ávido acúmulo de F-18 desóxi-fluoro-glicose, permitindo-nos concluir que PET e PET/CT de corpo inteiro é uma ferramenta valiosa no estadiamento e moninotoramento do tratamento do câncer de cólon. Nós continuamos a obter dados para possível introdução do PET de corpo inteiro e PET/CT "scanning" para o diagnóstico de carcinoma de colon e pólipos pré-cancerosos.

\section{REFERENCES}

Agress, H. et al. (2004), Radiology, 230, 417-422.

Pin, C. A. et al. (2000), Clinical Nuclear Medicine, 25 : (5), 370-371.

Chiehuan, Y.; Kaminski, M. D. et al. (2003), Clinical Nuclear Medicine, 28 : (1), 60-61.

Cohade C et al (2003), Direct comparison of 18 F-FDG PET and PET/CT in patients with colorectal carcinoma. J. Nuclear Med., 44, 1797-1803.

Falk, M. D. et al. (1994), Diseases of the Colon and Rectum, 37 : (2), 155-156.

Gambhir, S. S. et al. (2001), Journal of Nuclear Medicine, 42, 95-125.

Hongming Huang, MD, et al, Clinical Nuclear Medicine, Vol. 27, No. 9, 2002, pp. 628-632.

Joost P.H. Dreath, et al. European Journal of Nuclear Medicine, Vol 28, No 12, Dec 2001.

Larson, Steven et al, "PET/CT functional imaging of Esophageal and Colorectal Cancer." Cancer Journal, Jul-Aug 200410 (4) 243-250.

Selei Yasuda et al, Japanese Journal of Clinical Oncology, Vol 28, No 10, 1998, pp 638-640.

Selei Yasuda et al, The Journal of Nuclear Medicine, Vol 42, No 7, July 2001, pp. 989-992.

Yamada Tedataka, M. D. (2003), Textbook of gastroenterology. $4^{\text {th }}$ ed. v. 2. pp. 1959-1963.

Received: June 04, 2005;

Revised: July 14, 2005; Accepted: August 01, 2005. 